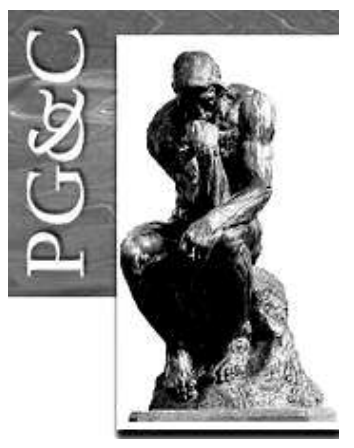

\title{
CLASSIFICAÇÃO DAS MANIFESTAÇÕES DE USUÁRIOS DE UM HOSPITAL PÚBLICO COM BASE NAS CINCO DIMENSÕES DETERMINANTES DA QUALIDADE
}

\author{
Tânia Oliveira Souto Dias \\ Mestre em Gestão em Sistemas de Saúde pela Universidade \\ Nove de Julho, Brasil. \\ E-mail: taniaodias@ig.com.br \\ Renato Ribeiro Nogueira Ferraz \\ Doutor em Ciências pela Universidade Federal de São Paulo, Brasil. \\ Professor da Universidade de Santo Amaro, Brasil. \\ E-mail: renatobio@hotmail.com \\ Evandro Luiz Lopes \\ Doutor em Administração pela Universidade Nove de Julho, Brasil. \\ Professor da Universidade Nove de Julho, Brasil. \\ E-mail: elldijo@uol.com.br

\section{Ivone Panhoca} \\ Doutora em Ciências pela Universidade Estadual de Campinas. Professora \\ da Universidade de Mogi das Cruzes, Brasil. \\ E-mail: i.panhoca@terra.com.br
}

\begin{abstract}
Resumo
Objetivo: Agrupar manifestações registradas por usuários de um hospital público com base nas cinco dimensões determinantes da qualidade, visando obter subsídios para criação de políticas internas voltadas à qualidade no atendimento. Metodologia: Utiliza uma abordagem qualitativa, com base na técnica de desk research, sendo o SERVQUAL escolhido como modelo/método base para coleta de dados em formulários de manifestação livre, oriundos de um programa de qualidade institucional. Resultados: Observa-se que, do total de manifestações registradas, a grande maioria constituiu-se de reclamações. A categoria profissional mais apontada foi a dos médicos, e o setor com mais queixas foi o pronto socorro adulto. Os aspectos de responsividade e empatia foram os mais citados. Conclusão: A ausência de institucionalização de políticas de qualidade e humanização no atendimento acarretam problemas organizacionais que influenciam negativamente na qualidade dos serviços prestados. Sugerese a formulação de estratégias que busquem alcançar melhores resultados em relação a qualidade dos serviços prestados pelo hospital.
\end{abstract}

Palavras-chave: Políticas Públicas. Gestão em Saúde. Qualidade. Atendimento. Saúde Pública.

\section{CLASSIFICATION OF PUBLIC HOSPITAL USER MANIFESTATIONS WITH BASIS ON THE FIVE QUALITY DETERMINANTS}

\begin{abstract}
Aim: This study aimed to group events recorded by users of a public hospital, based on five dimensions of quality, to gather information with the aim of create internal policies for quality of care. Methodology: We used a qualitative approach, based on desk research technique, using SERVQUAL as model/method, to collect data from free expression forms, originated from an institutional quality program. Results: It was observed that, of total registered events, the majority were complaints. The most pointed professional category was the doctors, and the sector with most complaints was adult assistance. Aspects of responsiveness and empathy were the most cited. Conclusion: The lack of institutionalization of quality and humanization in care policies lead to organizational problems that exerts negative
\end{abstract}


influence in quality of provided services. It is suggested formulation of strategies that seek to achieve better results regarding the quality of services provided by the hospital.

Keywords: Public Policies. Health Management. Quality. Service. Public Health. Strategy.

\section{INTRODUÇÃO}

No decorrer dos anos, as mudanças no setor de saúde foram marcadas pelo surgimento de novas propostas de trabalho e pela criação de práticas assistenciais atualizadas, dentre muitas outras atividades. A busca pela qualidade no atendimento ao paciente, mantendo-o satisfeito, seja no setor público ou privado, continua sendo um dos grandes desafios dos gestores da saúde.

Estudos sobre o tema "satisfação do consumidor" vêm sendo apontados como fatores cruciais para o sucesso de qualquer organização, visto que podem influenciar diretamente na lealdade do cliente (FARIAS; SANTOS, 2000). A lealdade do cliente está diretamente ligada à sua satisfação, que antecede à lealdade. Segundo os autores há dois elementos que determinam a escolha do cliente, sendo um deles a qualidade percebida e o outro o valor percebido. A qualidade percebida é a avaliação do cliente sobre o produto ou serviço, tomando por base o desempenho percebido. Já o valor percebido é determinado pelo "custo benefício", isto é, o preço pago pelo produto e sua relação com a qualidade do mesmo (GASTAL, 2005). Por sua vez, Milan e Trez (2005) definem como satisfação todas as experiências vividas pelo indivíduo, que compõem o presente, o passado e o futuro, sendo o julgamento das experiências futuras embasado nas expectativas e experiências vividas anteriormente.

Medeiros et al. (2017), avaliaram a satisfação do acompanhante quanto à qualidade da assistência prestada à criança hospitalizada. O estudo foi realizado numa unidade de internação pediátrica de um Hospital Universitário. Setenta acompanhantes de crianças internadas atenderam aos critérios de inclusão e responderam ao instrumento de coleta de dados, composto por um formulário com informações socioeconômicas e outro adaptado de satisfação dos usuários do Programa Nacional de Avaliação dos Serviços de Saúde. Do total, $45,7 \%$ relataram relativa demora no atendimento durante a internação da criança. Houve satisfação com o repasse de informações sobre o paciente $(88,6 \%)$ e com o tempo de visita $(75,7 \%)$, limpeza dos ambientes $(75,7 \%)$, porém, $65,7 \%$ não sabiam onde fazer reclamações ou sugestões, e 44,3\% desconheciam o nome do profissional que atendera seu filho. 0 estudo evidenciou a satisfação dos acompanhantes quanto à qualidade da assistência à criança internada, destacando-se oportunidades de melhoria referentes aos direitos dos usuários.

Os hospitais gerenciados pela Administração Direta (AD) seguem um modelo de gestão cuja avaliação de desempenho objetiva a melhoria dos processos institucionais. Esse instrumento de gestão é denominado "contrato de gestão", documento oficial onde metas são pactuadas pelos dirigentes dos hospitais (PERDICARIS, 2012). Os gestores dos hospitais da AD são orientados a utilizarem o "contrato de gestão", como estratégia gerencial. O grande desafio desses gestores é alcançar índices institucionais adequados em todos os níveis gerenciais e, para tanto, os planos de ação devem estar alinhados às estratégias globais do hospital (RODRIGUES et al., 2014).

A Instituição foco deste estudo é um conjunto hospitalar de alta complexidade, com uma enorme gama de processos de trabalho a serem gerenciados. Entretanto, segundo registros internos do Hospital (dados não publicados), tais processos não estão bem definidos ou mesmo disseminados entre as equipes, de modo que nem sempre garantem um padrão de

Perspectivas em Gestão \& Conhecimento, João Pessoa, v. 9, n. 2, p. 85-111, maio/ago. 2019. 
assistência considerada de qualidade. A ausência de políticas de qualidade impacta diretamente nos processos assistenciais e gerenciais da Instituição, fato este evidenciado nas manifestações registradas pelos usuários por meio dos diversos canais de comunicação disponíveis, como por exemplo, a ouvidoria e o Programa "Conte Comigo". Inúmeras são as dificuldades na manutenção das metas pré-estabelecidas no contrato de gestão da instituição citada, visto que a ausência de políticas de qualidade e humanização no atendimento, resultam em queixas de usuários dos serviços, estas manifestadas por meio das pesquisas de satisfação, realizadas pela Instituição.

Atualmente, diversos problemas permeiam a execução do Programa "Conte Comigo", especialmente relacionados a falta de comunicação entre os pares envolvidos, falta de retorno relacionado aos registros por parte do setor citado nos formulários, ausência de tomada de decisões com relação às reclamações mais frequentes, dentre outros. Nesse sentido, a presente pesquisa buscou realizar uma avaliação qualitativa das manifestações dos participantes do Programa "Conte Comigo", com base nas cinco dimensões determinantes da qualidade propostas por Parasuraman, Zeithaml e Berry (1988), visando fornecer informações estratégicas que poderão nortear ações de melhoria.

Cada vez mais as instituições de saúde vivenciam um ambiente de competitividade entre as organizações, exigindo que gestores inovem suas formas de gerenciá-las (VENDEMIATTI et al., 2010). Nesse sentido, a justificativa para o presente estudo se dá fundamentalmente pela importância que o sistema de saúde tem para a população do país, visto que os hospitais públicos são bens comuns a todos os cidadãos. Entende-se que os resultados oriundos da presente pesquisa fornecerão aos gestores do hospital uma visão macro de como planejar ações, buscando elevar a qualidade do atendimento, de forma a atingir as metas definidas no contrato gestão do hospital.

Partindo-se dos argumentos expostos até então, o objetivo central do presente trabalho foi categorizar as manifestações registradas pelos usuários do Programa "Conte Comigo" com base nas cinco dimensões determinantes da qualidade (PARASURAMAN; ZEITHAML; BERRY, 1988), buscando fornecer subsídios para criação de uma política interna de melhoria da qualidade. Ainda, pretendeu-se identificar as principais manifestações e classificálas como reclamações, elogios e sugestões, relacionadas aos serviços oferecidos e agrupar as manifestações por setor, por profissional envolvido e por serviço oferecido.

\section{REFERENCIAL TEÓRICO}

\subsection{Qualidade hospitalar}

\subsubsection{Qualidade e humanização no atendimento hospitalar}

$\mathrm{Na}$ área da saúde, a filosofia da qualidade não se diferencia dos padrões adotados nas indústrias, pois o cliente, em qualquer que seja o setor, anseia por qualidade e bom atendimento (VIEIRA et al., 2011). Entende-se por qualidade ou melhoria contínua da qualidade, como o conjunto de padronizações e resultados condizentes ao "erro zero", muito embora a perfeição ou a ausência de erros não esteja no alcance dos padrões humanos, mesmo que as buscas pelas melhores práticas reflitam o compromisso da organização com a filosofia da qualidade (FELDMAN; GATTO; CUNHA, 2005).

Segundo da Rocha et al. (2011), a gestão hospitalar não acompanhou o avanço e o crescimento das organizações e instituições de saúde, e novas técnicas de gerenciamentos não foram praticadas nos últimos tempos. A falta de investimentos em políticas preventivas, tanto em nível federal, como estadual e municipal, causa desconformidades que hoje são reconhecidas pelos gestores de hospitais. Diante de uma visão gerencial mais atualizada, nas

Perspectivas em Gestão \& Conhecimento, João Pessoa, v. 9, n. 2, p. 85-111, maio/ago. 2019. 
últimas duas décadas, a preocupação com políticas de qualidade e de acreditação hospitalar tem causado um verdadeiro "objeto de desejo" entre as organizações que atuam no sistema de saúde.

Barbosa e Brondani (2004), refletem a competitividade entre as organizações com o seguinte pensamento: "nos dias de hoje, existem três tipos de organizações: as que fazem acontecer, as que apenas observam acontecer e as que surpreendentemente se espantam com o que aconteceu". Os autores afirmam que, para fazer parte do grupo das empresas bemsucedidas, isto é, que "fazem acontecer", é fundamental que a organização priorize o planejamento estratégico, pois é nele que são direcionadas ações que possibilitam o alcance e cumprimento da missão, visão e valores institucionais. Ainda é colocado pelos autores supracitados que o planejamento estratégico contribui para os gestores como um importante instrumento norteador visando a diminuição de tomadas de decisões não assertivas.

Almeida (2001), define qualidade no setor de saúde como a sistematização dos processos organizacionais nos três níveis da esfera política, na busca da ética e técnicas embasadas nas melhores práticas de ações e procedimentos, proporcionando ao indivíduo conforto, bem-estar e amenização do sofrimento que pode ser gerado pela ausência de saúde.

Segundo Gitlow (1993), a qualidade é o julgamento feito pelos clientes sobre o produto ou serviço, levando em conta suas necessidades e expectativas sobre o mesmo. Grönroos (1995), afirma que a qualidade dos serviços é a percepção do cliente sobre o serviço ou produto.

Para o Ministério da Saúde (MS), a qualidade é condição indispensável no atendimento setorial. Com intuito de qualificá-la, o MS, juntamente com a Organização Pan-Americana de Saúde (OPS), adotou padrões mínimos de assistência na prevenção, promoção e recuperação da saúde. Também com a intenção de qualificar os serviços e melhorar os resultados de desempenho organizacionais, o MS incentivou as instituições a adotarem novos padrões de atendimento, sugerindo a participação destas em programas de acreditação (NASCIMENTO et al., 2008).

A qualidade no atendimento médico-hospitalar sempre foi uma das preocupações das instituições de saúde. Donabedian (1980, p. 77-125) apud Maria (2006, p. 85), foi o pioneiro no setor de saúde a estudar sistematicamente a qualidade dos serviços. 0 autor absorveu, com base na teoria de sistemas, a noção de indicadores de estrutura, processo e resultado, adaptando-os aos serviços hospitalares, e fazendo com que esta abordagem se tornasse um clássico no que diz respeito à condução de estudos que visam avaliar a qualidade oferecidas pelos serviços de saúde (MARIA, 2006).

A política de humanização é uma valiosa estratégia de gestão, devendo estar inserida nos diversos processos de atendimento do hospital. Segundo Rios (2009), a Política Nacional de Humanização (PNH), tem se mostrado como uma importante ferramenta de gestão para alcançar bons resultados nos serviços prestados. A humanização é hoje um tema atual nos serviços de saúde. Ideologias, teorias e programas de humanização são imprescindíveis para estes serviços. Ações de humanização, quando praticadas, tornam-se grandes diferenciais de gestão, já que a Instituição passa a ter um reconhecimento que a diferencia das demais. 0 atendimento estruturado humanizado melhora o atendimento global e, consequentemente, a qualidade dos serviços prestados passa a ser mais percebida pelos usuários (RIOS, 2009).

A PNH se baseia nos princípios que "sustentam" a Constituição reguladora do Sistema Único de Saúde (SUS), definida na Lei Orgânica da Saúde (8.080/90). Esses princípios estão definidos em três dimensões: a transversalidade, que se refere a uma maior comunicação e troca interativa entre os atores envolvidos; a indissociabilidade entre práticas de gestão e práticas de atenção à saúde, entendida como "inseparáveis", quando se atua em um destes campos; e por fim, o terceiro princípio, que é o protagonismo dos sujeitos e dos coletivos, que 
aposta na ação transformadora dos sujeitos em produzir saberes, práticas e intervenções singulares nos processos de trabalho (PASCHE; PASSOS, 2008).

Estrategicamente, a PNH tem sido o suporte fortalecedor do Sistema Público de Saúde, contribuindo para a melhoria da qualidade da atenção e da gestão da saúde no Brasil. Diante dessa reflexão, a PNH prioriza algumas ações essenciais para o desenvolvimento das políticas de humanização. Uma delas é contagiar equipes, gestores e usuários com ideias e diretrizes "humanizadas". Outra é o fortalecimento de trabalho em equipe multiprofissional, fomentando a transversalidade e a grupalidade (PASCHE; PASSOS, 2008).

Com o intuito de melhorar e "humanizar" os serviços de saúde nos hospitais, a PNH criou alguns dispositivos que, ao serem aplicados, enriquecem as práticas de produção de saúde. Como tais podemos citar: projeto terapêutico singular e projeto de saúde coletivo; sistema de escuta qualificada para usuários e trabalhadores da saúde; gerência de "porta aberta"; ouvidorias; grupos focais de pesquisa de satisfação; projeto "acolhendo os familiares / rede social participante"; visita aberta; direito do acompanhante; "acolhimento com avaliação e classificação de risco". Este último, refere-se a um processo dinâmico de identificação de pacientes que necessitam de tratamento imediato, de acordo com o potencial de risco, priorizado conforme a gravidade clínica do paciente, e não com base na ordem de chegada ao serviço. Esta classificação deve ser realizada por enfermeiros, pois considera-se que este é o profissional indicado para avaliar e classificar o risco dos pacientes que procuram os serviços de urgência, devendo ser orientado por um protocolo direcionador (DE SOUZA et al., 2011).

Segundo Coutinho, Cecílio e Mota (2012), há vários tipos de protocolos que direcionam o atendimento por meio de acolhimento com avaliação e classificação de risco. Entretanto, um dos mais conhecidos é o protocolo Manchester. O Sistema de Triagem Manchester, possui cinco categorias ou níveis. A cada categoria é atribuído um número, cor, nome e tempo-alvo máximo aceitável até o primeiro atendimento médico.

Windle e Mackway-Jones (2003), entendem que "triagem é um sistema de gerenciamento de risco clínico, implementado em todo o mundo para gerenciar fluxo de paciente com segurança, quando a necessidade exceder a capacidade".

Muitos serviços de atendimento de urgência convivem com grandes filas, onde as pessoas disputam o atendimento sem critério algum, a não ser a hora da chegada. A ausência de avaliação de riscos ou grau de sofrimento faz com que alguns casos se agravem na fila, podendo gerar sérios problemas decorrentes da falta de atendimento no tempo adequado (DOS SANTOS et al, 2014). Segundo a Política de Humanização, os benefícios de se implantar o "Acolhimento com Avaliação e Classificação de Risco", são imensuráveis.

\subsubsection{Qualidade percebida}

Segundo Jesus (2015), de acordo com o Ministério da Saúde os serviços de saúde tem como missão não apenas prestar atendimento aos que procuram os serviços, mas sim de atendê-los de forma a satisfazê-los, diminuindo ou eliminando suas necessidades, as quais os levaram a buscar o serviço. $O$ autor afirma que existe um aumento das expectativas e do grau de exigência de usuários que utilizam os serviços de saúde, e que, cada vez mais, estes são um importante determinante nas organizações assistenciais. O interesse de uma organização em procurar a qualidade dos seus bens ou serviços só fará sentido se esta for percebida pelo cliente.

Para Fadel e Regis Filho (2009), os consumidores buscam prestadores de serviços comparando as percepções que têm do serviço recebido com o serviço esperado, definindo o que se entende como qualidade de serviço percebida. Resultados satisfatórios de qualidade percebida são obtidos quando os serviços recebidos ou experimentados atendem às expectativas dos consumidores. Ainda segundo os autores, o prestador de serviços terá bons

Perspectivas em Gestão \& Conhecimento, João Pessoa, v. 9, n. 2, p. 85-111, maio/ago. 2019. 
resultados no negócio quando este entender as avaliações realizadas pelos clientes visto que, desta forma, poderá traçar diretrizes que influenciarão nos resultados almejados.

Cleto (2014), afirma que as organizações devem reduzir ao máximo as discrepâncias entre o que o cliente deseja e o que ele efetivamente recebe do serviço. Segundo Zeithaml, Bitner e Gremler (2014), os clientes não percebem a qualidade como um conceito unidimensional, ou seja, as avaliações dos clientes acerca da qualidade incluem percepções de múltiplos fatores ou dimensões, que agrupam os diferentes atributos do serviço.

Os autores Parasuraman, Zeithaml e Berry (1985), afirmam que a qualidade percebida é a relação entre as expectativas e a performance percebida de um serviço, e que o conhecimento sobre a qualidade de bens é insuficiente para a avaliação da qualidade de serviços. Segundo a visão de Lopes (2007),

Uma boa qualidade percebida é obtida quando a qualidade experimentada atende às expectativas do cliente, ou seja, à qualidade esperada. Portanto, o processo de avaliação da qualidade do serviço que o cliente faz é função de suas expectativas (qualidade esperada) e de sua percepção do serviço (qualidade experimentada).

2.1.3 Modelo teórico em qualidade percebida em serviços, os cinco Gaps.

Parasuraman, Zeithaml e Berry (1985), afirmam que o princípio dos gaps, baseado na expectativa e experiência como uma medida de qualidade de serviço, foi utilizado pela primeira vez no início da década de 80 por Lewis, seguido por Gronroos (1988). Este modelo foi embasado na ideia de que os consumidores avaliam a qualidade dos serviços segundo suas expectativas. A construção e desenvolvimento do modelo dos gaps passaram por muitas etapas, incluindo experiências com consumidores, por meio de grupos focais, entrevistas com executivos e estudos exploratórios, que muito contribuiu para o avanço no conhecimento sobre $o$ assunto.

Durante as pesquisas sobre o modelo dos gaps, participaram quatro organizações de diferentes seguimentos, sendo elas, banco de varejos, administradora de cartão de créditos, corretora de valores e empresa de reparos e manutenção de produtos. 0 tema norteador das discussões, tanto nos grupos focais quanto nas entrevistas, foi relacionado à qualidade percebida pelos consumidores e executivos entrevistados. Foi possível concluir que existem lacunas relacionadas à percepção e ao desempenho dos serviços, e que estas impactavam na percepção do cliente. Com base nesta conclusão, foi proposto um novo modelo de qualidade em serviços, no qual a qualidade percebida pelo cliente é constituída por cinco gaps (lacunas), descritos a seguir:

Gap1 - Associado ao nível hierárquico da organização, isto é, diferença entre as expectativas do consumidor e a percepção dos dirigentes, muitas vezes causada por falhas na comunicação, impactando negativamente na percepção da qualidade dos serviços disponibilizados.

Gap2 - Relacionado à dificuldade dos gestores em transformar os desejos e expectativas dos clientes em produtos e serviços disponíveis, muitas vezes pela falta de compromisso, resultando em baixa qualidade nos serviços e produtos oferecidos.

Gap3 - Relativo ao desempenho de serviços, processo interativo entre o cliente e o prestador, ligado diretamente a qualidade dos serviços. O gap3, é descrito pelos autores, como o responsável pela "saúde da empresa", pois a percepção de qualidade, é fundamental para satisfação e lealdade dos clientes nos serviços. Segundo Parasuraman, Zeithaml e Berry (1985), existem atributos chave para que uma organização tenha uma boa performance: trabalho em equipe, capacitação de funcionários, tecnologia disponibilizada a todos colaboradores,

Perspectivas em Gestão \& Conhecimento, João Pessoa, v. 9, n. 2, p. 85-111, maio/ago. 2019. 
ambiente de trabalho saudável, reconhecimento profissional, interação entre as partes, gestores e clientes e segurança de informação, todos fundamentais para garantia de bons resultados.

Gap4 - Quando há promessas não cumpridas, diferença entre o serviço prestado e a comunicação com o mercado. Pode ocorrer quando não há um planejamento de comunicação adequado entre coordenação e operação. Também podem ocorrer falhas de gestão muitas vezes envolvendo o setor de marketing, como por exemplo, uma propaganda exagerada, ou prometer demasiadamente sem ter condições de cumprir, propiciando ao cliente uma baixa percepção de qualidade.

Gap5 - É a lacuna do serviço esperado e do efetivamente percebido. A percepção de qualidade está diretamente ligada a atender ou superar as expectativas dos clientes, a avaliação alta ou baixa, dependente da experiência atual do consumidor. Este gap é considerado como uma função dos quatro primeiros, sendo, portanto, uma lacuna onde são avaliados os resultados contidos nos demais gaps.

Os idealizadores dos cinco gaps chegaram à conclusão de que, independentemente do tipo de serviço, os participantes da pesquisa usavam critérios muitos semelhantes para avaliar a qualidade dos serviços prestados. Portanto, estes critérios foram enquadrados em dez categorias, denominadas pelos autores como os "determinantes da qualidade de serviço". Como resultado, surgiu a escala SERVQUAL, instrumento criado para medir a expectativa genérica sobre o serviço estudado, bem como as percepções concretas dos clientes sobre o ponto de vista dos serviços da organização.

Com base no modelo de qualidade para serviços, ou seja, com base nos "determinantes da qualidade", Parasuraman, Zeithaml e Berry (1988), propuseram uma reformulação para o instrumento criado em 1985. A estrutura das dez dimensões da qualidade foi reduzida para cinco dimensões. A Tangibilidade, a Confiabilidade e a Presteza, foram mantidas da versão original. Competência, Cortesia, Credibilidade e Segurança foram consideradas como uma única dimensão, denominada Segurança. Acesso, Comunicação e Compreensão foram agrupadas na dimensão Empatia, totalizando cinco dimensões (LOPES, 2007). Essa nova estrutura agrupa todos os elementos determinantes da qualidade. Portanto, apesar de apresentar-se de forma compacta, atende todos os quesitos necessários para mensurar a qualidade dos serviços (PARASURAMAN; ZEITHAML; BERRY, 1988).

\subsubsection{Programas de acreditação hospitalar e a melhoria contínua da qualidade}

Acreditação é o procedimento de avaliação dos recursos organizacionais, voluntário, periódico e sigiloso, que objetiva garantir a qualidade da assistência através de padrões previamente estabelecidos. Os padrões podem ser mínimos ou mais elaborados, definindo diferentes níveis de satisfação (BITTAR, 2000). No Brasil, existe o "Manual Brasileiro de Acreditação" que é validado pelo MS, sendo este gerado a partir da criação da Organização Nacional de Acreditação (ONA) e seus parceiros. A criação do referido manual objetivou fornecer os direcionamentos necessários para que as organizações prestadoras de serviços de saúde se adequassem e obtivessem uma certificação de adequação dos processos institucionais, sendo esta classificada em três diferentes níveis. O primeiro nível se refere a processos básicos de trabalho. As exigências desse nível são menores e estão associadas ao exercício profissional e condições mínimas indispensáveis para a prestação da assistência médico-hospitalar, embora sejam avaliados todos os processos como liderança, gestão de pessoas, gestão administrativa, gestão de suprimentos, processos de diagnóstico, processos estruturais, apoio técnico, logística e infraestrutura, sempre com o foco na gestão de qualidade. Os avaliadores têm a missão de percorrer toda a unidade de saúde, avaliando setores como unidades de internação, atendimento ambulatorial, atendimento emergencial,

Perspectivas em Gestão \& Conhecimento, João Pessoa, v. 9, n. 2, p. 85-111, maio/ago. 2019. 
atendimento cirúrgico e obstétrico, atendimento neonatal, unidades de tratamentos intensivos e demais locais. O segundo nível só pode ser avaliado nas instituições que passaram pelo processo de acreditação nível 1 e que foram aprovadas nessa acreditação. As exigências do nível 2 são condizentes com padrões de qualidade adotados nas "boas práticas" médicohospitalares, focando o direcionado na segurança do paciente. O selo de acreditação é emitido como "Acreditação Plena". Para buscar o selo de acreditação nível 3, igualmente aos demais níveis, a Instituição deve ter sido aprovada nos demais níveis. Nesse, as exigências são de "padrão de excelência", sendo estas correspondentes à qualidade total em todos os processos organizacionais (DA ROCHA et al., 2011).

Segundo Manzo, Brito e dos Reis Corrêa (2012), o Manual Brasileiro de Acreditação Hospitalar é um instrumento de avaliação da qualidade organizacional, sendo que este é subdividido em seções e subseções. As seções representam os serviços, setores ou unidades. As subseções tratam do escopo de cada serviço, setor ou unidade, segundo três níveis, do mais simples ao mais complexo. Cada subseção é composta por padrões que procuram avaliar estrutura, processo e resultado dentro dos setores ou unidades avaliadas. Os autores afirmam que o modelo da Organização Nacional de Acreditação (ONA), segue algumas regras como, um nível superior só é alcançado quando o anterior tiver sido atingido, isto é, deve-se seguir a ordem de avaliação sendo eles apresentados pelos níveis 1, 2 e 3.

É importante ressaltar que existem vários programas de acreditação, como por exemplo, o Joint Comission on Accreditation of Hospitals (JCl), Acreditação Canadense, Programa de Controle da Qualidade Hospitalar (CQH), patrocinado pala Associação Paulista de Medicina (APM) e pelo Conselho Regional de Medicina do Estado de São Paulo (CREMESP), dentre outros, considerados excelentes programas de acreditação hospitalar, todavia não discutidos aqui por não se constituírem no foco do presente trabalho.

Diversas razões levam os gestores a buscar a acreditação, sendo elas evidenciadas no cotidiano dos hospitais. Infelizmente, as instituições de saúde enfrentam problemas gerenciais desafiadores. Gestores preocupam-se cada vez mais com a gestão da qualidade para melhoria dos processos organizacionais, processos de trabalho muitas vezes se encontram mal definidos, existe considerável crescimento de queixas relatadas em ouvidorias, observa-se insatisfação global de pacientes com os serviços oferecidos. Tais contratempos, dentre outros, fazem parte do cenário atual da saúde no Brasil. A despeito de tais inconformidades, observase que muitos gestores estão "abraçando" a qualidade como diretriz institucional. Por exemplo, em uma pesquisa realizada em 154 hospitais, cujo objetivo principal era conhecer os motivos pelos quais os hospitais brasileiros buscavam implantar processos de acreditação, e onde todos os hospitais analisados estavam inseridos num dos três programas de acreditação, que são a Organização Nacional de Acreditação, a JIC ou a Acreditação Canadense, foi verificada unanimidade com relação aos resultados que indicaram o motivo pela busca da acreditação hospitalar, sendo a segurança do paciente o principal elemento motivador para que todos apostassem numa filosofia de qualidade institucional (ARAÚJO; FIGUEIREDO; FIGUEIREDO, 2013). Segundo Vendramini et al. (2010), "segurança do paciente" é hoje uma das maiores preocupações dos gestores de saúde em todo o mundo. Postula-se que não é raro ocorrer erros de conduta em pacientes cujas causas poderiam ser evitadas. Estima-se que um em cada seis pacientes internados em hospitais é vítima de algum tipo de erro.

Muitos hospitais demonstraram resultados de sucesso ao adotarem como política institucional a qualidade no atendimento. Experiências vivenciadas por dois hospitais Brasileiros, Santa Casa de Misericórdia de Porto Alegre - RS e Unidade de Cardiologia do Hospital São Paulo da Universidade Federal de São Paulo - SP, mostraram que, ao implantar a gestão de qualidade em suas instituições, percebem-se melhoras nos indicadores de desempenho. $\mathrm{O}$ novo modelo possibilitou à gestão atender melhor às necessidades dos clientes, bem como dos membros da organização, resultando na satisfação dos clientes 
externos nos serviços do hospital (BALSANELLI; JERICÓ, 2005). O Hospital de Clínicas de Porto Alegre, RS, também apostou na política de gestão pela qualidade ao implantar os indicadores de qualidade assistencial, tornando-os instrumentos gerenciais para a melhoria contínua do atendimento. $\mathrm{O}$ autor afirma ainda que a consolidação da cultura dos indicadores na prática assistencial melhorou a avaliação de riscos e segurança do paciente, tornando-as mais gerenciáveis no cenário assistencial (NASCIMENTO et al., 2008).

Outro exemplo de compromisso com a qualidade foi apresentado por Silva (2010), que relatou a experiências vivenciada entre duas instituições bancárias e de intermediação financeira, na cidade de Crissiumal - RS, onde concluíram que a satisfação de clientes foi consequência de um conjunto de atitudes e políticas adotadas pela Instituição, sendo que o custo benefício é fator relevante para grande parte dos clientes. Para alguns, a atenção e a cordialidade dispensada, juntamente com o suprimento de suas necessidades, tornaram-se motivos para que este mantivesse fiel à Instituição. A pesquisa também demonstrou que, ao personalizar os serviços com a intenção de satisfazer seus clientes, gera-se uma relação de fidelização entre as partes, essencial para a sobrevivência das organizações.

\subsection{Satisfação do cliente}

\subsubsection{Definições de satisfação de clientes}

Para Tontini (2008), a satisfação de clientes é fator crítico para o sucesso dos negócios, e as empresas se esforçam para tal. Porém, é necessário atender suas necessidades explícitas e implícitas por meio do conjunto de características ou atributos do serviço. Para isso, saber do cliente o que realmente ele considera satisfatório e imprescindível em um serviço é fator crucial para a obtenção de bons resultados.

Nos dias atuais, a competitividade entre as organizações está cada vez mais aparente. Instituições fortes e com potencial de sucesso no mercado surgem a todo momento, superando até mesmo as empresas já estabilizadas. O ambiente competitivo impulsiona as disputas de mercado, tornando a qualidade a exigência primordial dos clientes. Atender com qualidade deixou de ser um atributo da organização, passando a ser condição sine qua non para sobrevivência nos negócios. Diante de mudanças e exigências de mercado, no ano de 1976, ocorreu em Chicago a primeira conferência sobre pesquisa de satisfação, onde foi debatida e discutida a maior preocupação da época, que era o comportamento do comprador diante de novas perspectivas do mercado. Tomou-se por foco a necessidade de se ter um posicionamento reativo diante das reclamações dos clientes com o intuito de se alcançar melhores resultados. Na década de 1980, cresceu ainda mais a preocupação dos empresários em compreender quais atributos influenciariam os clientes no momento da compra, pois já na época os donos de negócios perceberam o quanto a satisfação influenciava os clientes no momento da recompra do produto. Segundo o autor, a satisfação do cliente passou a ter suma importância no meio empresarial, especialmente pelo fato desta estar diretamente ligada à rentabilidade e ao lucro do negócio em longo prazo (BEBER, 1999).

A satisfação do cliente é definida por Oliver (1999), como a avaliação do consumidor que, após utilizar o produto ou serviço por única ou múltipla vezes, entende que este supriu seu propósito. Para de Paula Baptista, da Silva e Goss (2011), a satisfação de clientes tem importância explícita no setor de marketing, pois gera resultados na retenção de clientes, fator impactante na relação custo-benefício para a organização.

Muitas empresas dos mais diferentes negócios têm se preocupado em "encantar" seus clientes, pois a satisfação é um dos grandes diferenciais para a manutenção e o sucesso empresarial. Oliver (1999), firma que a lealdade do cliente está diretamente ligada à satisfação, e que comportamentos personalizados influenciam na aprovação dos produtos ou

Perspectivas em Gestão \& Conhecimento, João Pessoa, v. 9, n. 2, p. 85-111, maio/ago. 2019. 
serviços, sentimento de prazer, afeto e justiça. No entanto implicações gerenciais são fatores fundamentais para alcançar a satisfação dos clientes e, por esta razão, os gestores das organizações devem se comprometer na elaboração de estratégias eficazes que "encantem" seus clientes e determinem sua lealdade ao serviço.

\subsubsection{Fatores que influenciam a satisfação do cliente}

A qualidade é um fator determinante quando se discute satisfação e fidelidade de consumidores. Indivíduos buscam satisfações múltiplas no seu dia-a-dia, sendo que estas comumente estão relacionadas com algumas condições de julgamento do consumidor, como localização geográfica, fatores ambientais como a decoração, sons, aromas, iluminação e configurações visíveis do produto ou serviço desejado. Todos estes critérios de avaliação influenciam diretamente nos resultados de clientes satisfeitos (KERBER, 2015).

Em pesquisa realizada em quatro hospitais da cidade de Porto Alegre - RS, cujo objetivo central se resumiu em identificar os principais atributos que levam à satisfação do cliente, foram identificados como importantes fatores a atenção dispensada durante o momento da internação, a rapidez no atendimento, o bom relacionamento com a equipe médica, a competência da equipe de enfermagem, o cuidado no transporte do paciente, a qualidade da limpeza e a cortesia no atendimento, dentre outros. Nesse estudo, concluiu-se que a identificação e a compreensão dos atributos relevantes para a manutenção da satisfação dos clientes em saúde dependem efetivamente de uma gama de ações gerenciais vigentes em cada Instituição (DE MOURA; LUCE, 2004).

Outro estudo realizado em dois hospitais, sendo um público e um privado, onde se buscou identificar fatores que influenciavam a satisfação do cliente na internação, verificou que em ambos os hospitais os serviços de enfermagem, nutrição e médico foram critérios relevantes na avaliação do cliente. Entretanto, o que mais pesou, segundo a opinião do usuário, foi o resultado do atendimento da enfermagem, justificado no próprio trabalho pela maior permanência da equipe de enfermagem com o doente no período de internação, quando comparada às outras equipes atuantes no hospital (TONTINI et al., 2013).

Pesquisas de satisfação realizadas pela Secretaria da Saúde de Pernambuco também mostraram como resultados alguns atributos que influenciaram na satisfação dos usuários, como a habilidade dos profissionais, o sigilo das informações pessoais e o respeito à intimidade. Entretanto, a pesquisa também teve como resultado atributos de insatisfação relevantes na opinião do usuário, sendo que um deles foi a demora no atendimento e o outro a falta de medicamentos. Em relação à dificuldade de acesso aos medicamentos, a Secretaria da Saúde de Pernambuco ressalta que questões relativas à assistência farmacêutica devem ser reavaliadas, e com relação à demora do atendimento, estudos futuros sobre o tema devem ser realizados em busca de maior resolutividade para o setor (GOUVEIA et al., 2011).

Tontini et al. (2013) afirmam que no Brasil são muitas as dificuldades enfrentadas no setor público, como a falta de recursos e a ingerência dos processos organizacionais, justificando os resultados insatisfatórios nas instituições governamentais. A baixa remuneração dos serviços, a ausência de capacitação profissional, a falta de investimento em manutenção e muitos outros problemas, refletem na insatisfação de usuários. Contudo, a população continua tendo necessidades que ultrapassam todas estas questões e, ao utilizarem os serviços de saúde, entendem que seus direitos devem ser cumpridos. Pesquisas de satisfação apontam atributos relevantes de aprovação ao serviço, sendo que um deles se refere à tecnologia de última geração, sendo esta considerada pelos clientes como condição indispensável para o sucesso terapêutico. Outro atributo está relacionado ao número de pessoal qualificado, também uma condição primordial na ótica do usuário. Por último, porém não menos importante, cita-se a importância da existência de instalações modernas. Ainda

Perspectivas em Gestão \& Conhecimento, João Pessoa, v. 9, n. 2, p. 85-111, maio/ago. 2019. 
segundo os autores, entende-se que estes atributos foram considerados como condições sine qua non para que o usuário avalie os serviços inseridos em assistência de qualidade.

Em uma pesquisa realizada no Pronto Socorro de um hospital público de ensino, cujo objetivo foi avaliar a opinião dos usuários frente à qualidade da estrutura e do processo de atendimento por meio de entrevistas individualizadas com os usuários, concluiu-se que, por meio de lideranças competentes, é necessário melhorar a qualidade da estrutura local, principalmente no que se refere ao excesso de ruídos e de iluminação. Quanto aos processos que necessitam de intervenções emergenciais, a segurança do paciente foi conceituada como maior prioridade para alcançar a satisfação dos clientes atendidos (SELEGHIM et al., 2012).

O aumento das expectativas e do grau de exigência dos usuários dos serviços de saúde é cada vez mais um importante determinante nas organizações prestadoras desses serviços. Seja qual for a estratégia gerencial, é essencial investir na política de qualidade e política de humanização no atendimento, pois estas diferenciam os serviços de saúde e respondem as expectativas de seus clientes (JESUS, 2015).

\subsection{Definição de gestão}

A administração, também conhecida como gerenciamento ou gestão, supõe a existência de uma organização a ser administrada ou gerida, ou seja, a união de pessoas que se relacionem num determinado ambiente, seja ele físico ou não, direcionadas para um objetivo comum, que é a organização (CORREA; CAON, 2002).

Segundo Martins e Waclawovsky (2015), gestão compreende medidas de planejamento, alocação de recursos, avaliação de desempenho e outras atividades fundamentadas nas teorias administrativas, isto é, organização de processos, trabalho em equipe, padronização de procedimentos, coordenação, direção e controle. Araujo, Figueiredo e Figueiredo (2015), afirmam que os desafios gerenciais são preocupações comuns entre os gestores de serviços. Cada vez mais os gestores se preocupam com a melhoria dos processos organizacionais.

\subsubsection{Gestão hospitalar, lideranças e competências}

Dos Santos e Arruda (2012), afirmam que a evolução da gestão em hospitais está diretamente relacionada à história dos hospitais e da medicina. É sabido que no Brasil os serviços de saúde eram considerados instituições de caridade, sendo comandadas por religiosos, médicos e enfermeiros, ou até mesmo por membros da comunidade. Não se pensava nesses serviços como negócios ou empresas de saúde, muito menos na lucratividade dessa atividade. Por não considerarem uma atividade profissional, acreditavam que o aprendizado administrativo provinha de experiências do cotidiano, e não se pensava na capacitação profissional na área gerencial. Os autores concordam que, para se administrar uma organização de saúde, não necessariamente se precisa de um profissional graduado em medicina, embora se acredite que uma organização de saúde sem um administrador especializado pode correr sérios riscos de insucesso gerencial. Rizzatti, Pereira e Amaral (2012), corroboram que é indispensável que na gestão em serviços de saúde haja líderes competentes com formações e conhecimentos teórico-práticos de gestão hospitalar.

Rizzatti, Pereira e Amaral (2012), afirmam que todo líder tem seguidores e que estes "imitam" suas ações. O verdadeiro líder influencia pessoas ao seu redor e que esse fato não está correlacionado com a hierarquização organizacional, pois nem todo comandante é o líder e vice-versa. Segundo os autores, existem indivíduos que, mesmo exercendo cargos de chefia, não lideram seus subordinados. Esses chefes conseguem a "obediência" de seus funcionários

Perspectivas em Gestão \& Conhecimento, João Pessoa, v. 9, n. 2, p. 85-111, maio/ago. 2019. 
por meio de coação ou por interesses particulares das pessoas a quem chefiam. Entretanto, há pessoas que, mesmo sem "autoridade" hierárquica, influenciam outras pessoas.

Vendemiatti et al. (2010), afirmam que o setor saúde tem sofrido impactos significativos quanto à forma de gerenciamento. Nos dias atuais, as cobranças são frequentes para que a alta liderança se capacite e profissionalize em gestão. A gestão da qualidade está inserida nos novos modelos gerenciais, visto que objetivos e metas devem ser alcançados sistematicamente. Para isso ocorrer, mudanças estruturais são invitáveis em organizações conservadoras. A profissionalização dos processos gerenciais nas organizações de saúde tornou-se condição prioritária para resultar num bom desempenho dentro do mercado que, por sua vez, se torna cada dia mais competitivo. Como nos demais seguimentos organizacionais, na área da saúde há muitos conflitos, e estes devem ser desdobrados por lideranças comprometidas e competentes da Instituição. Entretanto há dualidade entre partes distintas dentro de uma mesma Instituição. Lideranças com formações acadêmicas em saúde, como por exemplo, médicos e enfermeiros, tendem a gerenciar os processos assistenciais baseando-se em seus conhecimentos específicos de urgência, emergência e gestão de riscos. Já os profissionais com formação gerencial, entendem os processos assistenciais de forma bem diferente, e a visão desses engloba também o contexto totalizado de uma organização, como seus custos e resultados empresariais.

O trabalho em equipe torna-se um grande desafio para a alta liderança, pois não é nada fácil integrar várias culturas dentro de uma mesma estrutura organizacional, e dirigi-las de modo que alcancem objetivos comuns à empresa.

Outro desafio na gestão organizacional está relacionado com as competências gerenciais. Segundo Fernandes (2012), a competitividade entre as diversas organizações do mercado tem induzido os gestores a buscarem profissionais cada vez mais competentes e qualificados que possam atender quesitos de qualidade exigidos no meio profissional. Segundo o autor, considera-se um profissional competente aquele que demonstre pró-atividade nas atividades empresariais, isto é, o indivíduo vai além do que se espera dele, estando acima de tudo o embasamento, o conhecimento e o domínio técnico como grandes norteadores das suas ações. $O$ autor também faz uma reflexão sobre o indivíduo competente, postulando que este geralmente é "percebido" pelos demais membros colaboradores por suas atitudes resolutivas.

Da Silva, Matias e Gonzalez (2014), afirmam que competência é uma capacidade específica que um indivíduo tem de realizar uma ação em um nível de habilidade capaz de alcançar o efeito desejado. Segundo os autores, esta ação contribui positivamente para o alcance dos objetivos estratégicos da empresa. A preocupação com a gestão por competências e com a maneira como as organizações mobilizam seus recursos, revela a diferença de desempenho entre as organizações. Ainda, há necessidade de se investir em melhoria contínua nos processos de gestão de pessoas, pois é por meio destes que os colaboradores da organização podem ser mais bem coordenados e integrados, a fim de se atingirem os seus objetivos organizacionais.

Fleury e Fleury (2001), definem competência profissional como, "saber agir responsável e reconhecido que implicam mobilizar, integrar, transferir conhecimentos, recursos, habilidades, que agreguem valor econômico à organização e valor social ao indivíduo".

Buscar desempenho operacional e organizacional passou a fazer parte da competência gerencial das organizações. Por meio de planejamentos estratégicos institucionais, concorrentes buscam constante crescimento e principalmente a manutenção de suas clientelas. Para isso, satisfazer seus clientes passou a ser condição fundamental para torná-los leais. Contudo, os hospitais contemporâneos demonstram uma preocupação exagerada em mostrar benfeitorias, como melhores equipamentos e modernas instalações, embora se saiba

Perspectivas em Gestão \& Conhecimento, João Pessoa, v. 9, n. 2, p. 85-111, maio/ago. 2019. 
que um hospital não depende só da aparência externa para ser aprovado pelos clientes, mas sim de ter processos de trabalho seguros e estruturados que transmitam confiabilidade para seus clientes (RODRIGUES, 2001).

Segundo Dussault (1992), melhorar os serviços de saúde implica utilizar os recursos disponíveis eficientemente. Este é um grande desafio na maioria dos países, sendo representado pela competência gerencial dos recursos, atendendo as necessidades da população e diminuindo o desequilíbrio geográfico por meio de melhorias no acesso, e disponibilizando médicos, enfermeiros, insumos e equipamentos necessários em locais carentes de serviços. $\mathrm{O}$ autor afirma ainda que esse desafio é maior em países pobres, já que a falta de recursos humanos e financeiros contribui muito para a ineficácia de atendimento.

\subsubsection{Modalidades de gestão em hospitais públicos}

Incentivado por países estrangeiros, o Brasil passou a rever o modelo gerencial de suas organizações. $\mathrm{O}$ objetivo estava em facilitar os processos gerenciais por meio de processos facilitadores na compra de insumos e produtos, na contratação e dispensa de recursos humanos e nos desdobramentos financeiros. Além disso, era necessário estimular principalmente os líderes organizacionais a participar de planos e ações que contemplassem a qualidade da assistência prestada, buscando a obtenção de melhores resultados no setor. 0 enfoque gerencial era embasado na eficiência dos serviços e, com isso, surgiu a ideia de buscar no setor privado exemplos de melhores práticas, benchmarking setorial, que deveriam ser adotados na nova gestão pública. Também com exemplos de sucesso organizacional, foram propostos sistemas de custos e auditorias dos processos institucionais, separação de verbas específicas de investimento, além de mudança na "cultura organizacional" na busca de qualidade total (IBAÑEZ et al., 2001).

Diante do exposto e objetivando adequar recursos para obter resultados satisfatórios, a gestão pública de hospitais adota dois grandes modelos gerenciais. Um deles é o modelo da Administração Direta (AD), e o outro são os hospitais denominados Organizações Sociais de Saúde (OSS). As OSS são instituições sociais, de utilidade pública e sem fins lucrativos, que trabalham de forma diferenciada quanto ao modo de gerenciar os processos organizacionais. Já os hospitais pertencentes à AD são subordinados à Secretaria Estadual da Saúde (SES), que por sua vez possui uma Coordenadoria de Serviços de Saúde (CSS), responsável por gerenciar os hospitais pertencentes à Secretaria (PERDICARIS, 2012).

Com relação a melhor modalidade de gerenciamento de hospitais públicos, Pacheco (2006), afirmava à época que a AD estaria se adequando ao modelo de "contrato de gestão", e os resultados apontavam para uma evolução significativa no desempenho das instituições de saúde, especialmente porque a inserção e o monitoramento de indicadores passaram a ser instrumentos essenciais para tomada de decisões gerenciais.

Segundo de Sousa et al. (2012), conhecer e monitorar indicadores como número de internações, permanência, rotatividade no leito, tipo de atendimento, número de procedimentos realizados, dentre outros, permite a criação de estratégias visando a sistematização do atendimento com qualidade, permitindo assim uma adequação do número de leitos e de profissionais necessários para, de maneira adequada, prestar os cuidados necessários aos pacientes.

Um projeto intitulado "choque de gestão", realizado no Estado de Minas Gerais, foi um marco no qual dirigentes e colaboradores da área da saúde firmaram um "acordo de resultados", onde o compromisso pelo cumprimento das metas em qualidade se tornou pacto entre esses atores, com resultados bastante positivos os hospitais. Também em Pernambuco, a iniciativa de alguns gestores de instituições de $A D$, no intuito de articular dois campos de 
tecnologia, a tecnologia de gestão e a tecnologia da informação, contribuiu de maneira bastante satisfatória no que diz respeito à adequação tecnológica dos hospitais.

Independente da modalidade gerencial dos hospitais, se OSS ou AD, a competência é fator prioritário para o sucesso de uma organização. Brandão e Guimarães (2001), definem competência como "atitudes identificadas como relevantes para a obtenção de alto desempenho em um trabalho específico ao longo de uma carreira profissional". Em busca de melhorar o desempenho das organizações públicas, em 1995, foi criado o Plano Diretor de Reforma do Aparelho do Estado (PDRAE), sob a liderança do Ministério Público, que objetivou implantar uma nova ferramenta gerencial para melhoria dos resultados em saúde, que foi denominado "contratualização da rede hospitalar". Desde então, o "contrato de gestão" tornou-se um instrumento básico que norteia os processos institucionais, sendo oficializado por meio documental onde existem metas e prazos pactuados entre o poder público e a organização social. No caso de não cumprimento desse acordo, são gerados multas e desacordos entre as partes. Na documentação do contrato devem constar todos os acordos pactuados, como a redefinição da missão organizacional, a identificação precisa de produtos e clientes, os objetivos e metas estabelecidas, a estrutura organizacional, a metodologia de planejamento, a avaliação de desempenho, os mecanismos de informatização, os recursos humanos, os custos e os investimentos.

O contrato de gestão também pode ser definido como ferramenta gerencial da administração por objetivos ou administração sistêmica por objetivos e resultados. Outro autor define também o documento gerencial como compromisso negociados e acordados entre as partes (IBAÑEZ et al., 2001).

Implantar um modelo de gestão como o contrato de gestão nas organizações públicas de saúde, apresentava como objetivo principal monitorar e avaliar o desempenho institucional para tomada de decisões resolutivas. A princípio o projeto foi iniciado somente nas OSS, que posteriormente estendeu-se para os hospitais $A D$, com o mesmo objetivo, melhor a gestão pública na saúde. Na época estudos comparativos demonstraram que hospitais gerenciados pelas OSS apresentavam melhor desempenho nas atividades em relação ao desempenho dos hospitais da AD, que apontavam deficiências, justificadas pelo modelo de gestão conservador (PERDICARIS, 2012).

Contudo, apostar em um novo modelo gerencial nos hospitais de $A D$, faria parte de uma visão gerencial inovadora. Segundo Perdicaris (2012), o fato dos hospitais sob AD terem indicadores mais "consolidados" em decorrência aos anos de experiência em gestão pública, traz uma vantagem em relação à confiabilidade da coleta de dados, visto que esta prática já era vivenciada nas $A D$, porém não gerenciadas. Outra vantagem dos hospitais da $A D$ diz respeito à criação de um "grupo de controle", que possibilita um comparativo importante para avaliação de resultados, já que somente 15 dos 29 hospitais sob AD avaliados fazem parte desse projeto de mudança do modelo gerencial (PERDICARIS, 2012).

\subsubsection{Fatores relevantes para alcançar sucesso gerencial}

Leonardo (2002) afirma que a gestão de recursos humanos é fator crucial para o sucesso organizacional, e que empresas bem-sucedidas adotam uma filosofia de bom relacionamento com seus clientes internos e externos. Portanto, os modelos retrógrados devem ser reavaliados, pois, segundo o autor, o tratamento personalizado aos colaboradores de uma organização deve ser a forma adotada de relações humanas, mesmo porque esta retém talentos profissionais, fato este primordial para o alcance dos melhores resultados.

No ambiente empresarial, a tecnologia da informação (TI) tem sido considerada uma importante ferramenta de gestão, e um fator decisivo para o sucesso de uma organização. Nos dias atuais, esse instrumento é utilizado como estratégia competitiva entre os concorrentes de 
mercado. Buscar inovações e obter projetos avançados diferencia a Instituição e propicia aos gestores informações relevantes para tomada de decisões necessárias. Resultados apontam que a TI é capaz de melhorar o desempenho dos gestores das organizações, e este, por sua vez, impacta na economia organizacional, gerando vantagens competitivas no mercado setorial. Principalmente empresas de grande porte não sobrevivem sem esta importante ferramenta, já que ela promove uma gestão eficaz e, consequentemente, maiores oportunidades de sucesso (JUNIOR; PENHA; SILVA, 2013).

Segundo Barbosa e Brondani (2004), estudar o mercado, ou seja, analisar o ambiente interno como também o externo, é fator relevante para alcançar bons resultados organizacionais. Independente do modelo de gestão adotado pela Instituição, é fundamental que os gestores de todos níveis hierárquicos estejam cientes quanto aos seus pontos fortes e, principalmente, seus pontos fracos dentro dos processos organizacionais, cabendo a estes traçar melhorias sistemáticas para se manterem no mercado.

De Oliveira (2012) afirma a importância do desenvolvimento gerencial nas diversas áreas de atuação, e que este ganha destaque em todos os seguimentos empresariais. A formação e a capacitação em gestão passaram a ser condições fundamentais para obtenção de sucesso organizacional. Desde a década de 1990 já se enfatizava esse atributo gerencial, pois já era entendido que, com a compreensão das teorias administrativas, os gestores tornavam-se mais resolutivos. $\mathrm{O}$ autor afirma também que há quase vinte anos, estudiosos já apontavam a necessidade de intensificar treinamentos em habilidades gerenciais para a alta direção organizacional.

O sucesso gerencial de uma Instituição hospitalar está no saber aproveitar os recursos disponíveis da melhor maneira possível, sejam eles recursos estruturais, recursos humanos e financeiros. Todos devem ter como objetivo único o cumprimento da missão organizacional. Os hospitais deveriam ser gerenciados como empresas de saúde, com equipes profissionalizadas para atingir resultados satisfatórios, frisando a necessidade de os executivos organizacionais serem capacitados em gestão, já que dessa forma haverá maior entendimento quanto aos processos de trabalho de hospitais, quanto à importância das padronizações assistenciais, além da fundamental importância de se medir os resultados por meio de indicadores de desempenho. Estes e outros elementos gerenciais são elementos indispensáveis que fazem total diferença nos resultados finais de uma organização de saúde (COLAUTO; BEUREN, 2003).

\section{MÉTODO}

Trata-se de um estudo de caso retrospectivo, exploratório e descritivo com abordagem qualitativa. $O$ trabalho ocorre um único hospital público de Administração Direta, localizado na região metropolitana da cidade de São Paulo - SP, pertencente à Secretaria de Estado da Saúde, cuja subordinação é da Coordenadoria de Serviços de Saúde. Utilizou-se para coleta dos dados a técnica de desk research, que avaliou 142 formulários de manifestação livre, referentes ao período de 01 de dezembro de 2014 a 30 de abril de 2015, oriundos de um programa institucional denominado "Conte Comigo".

A análise dos dados seguiu um procedimento amplamente difundido pela literatura, no qual dois avaliadores fizeram a leitura e a compreensão individual do texto relatado em todos os formulários de queixas, elogios e sugestões relativos ao período indicado. Ambos avaliaram os documentos em sua totalidade e, em seguida, suas percepções foram comparadas. Caso os avaliadores apresentassem divergências na avaliação, os formulários eram encaminhados para um terceiro avaliador, que também forneceu seu parecer final. Esta medida de segurança visou garantir uma interpretação fidedigna dos dados por todos os avaliadores. O terceiro avaliador convidado também recebeu as mesmas instruções dos avaliadores 1 e 2 , afim de que

Perspectivas em Gestão \& Conhecimento, João Pessoa, v. 9, n. 2, p. 85-111, maio/ago. 2019. 
fosse seguido o mesmo modelo de análise dos dados. Os avaliadores são oriundos de um programa de pós-graduação stricto sensu com área de concentração na gestão de instituições de saúde.

Nenhum critério de exclusão de formulários necessitou ser observado. Os dados obtidos com o desk research foram tabulados com base nas cinco dimensões de qualidade, ou seja, os aspectos tangíveis, a confiabilidade, a responsividade, a segurança e a empatia, que consideram as expectativas dos clientes com relação a um determinado serviço frente à percepção de qualidade do serviço recebido.

O estudo foi submetido ao Comitê de Ética em Pesquisa da Instituição na qual foi realizado, sendo aprovado de acordo com o parecer consubstanciado $\mathrm{n}^{\circ}$. 1.297 .483 de $15 / 10 / 2015$, por obedecer às diretrizes éticas e legais previstas na resolução 466/2012 do Conselho Nacional de Saúde.

\section{RESULTADOS}

Vale ressaltar aqui que foram avaliados 142 formulários do programa "Conte Comigo" que, no total, apresentaram 283 manifestações, que foram classificadas como reclamações, elogios ou sugestões. As manifestações consideradas como não identificadas nesta avaliação, compreenderam aquelas cujas caligrafias não puderam ser decifradas, e também aquelas que não se dispunham a fornecer informações relacionadas ao intuito para o qual os formulários estavam disponíveis ( $n=17 ; 6 \%$ dos registros). Estas foram subtraídas do total da amostra inicial, quando então passaram a ser consideradas como amostra válida para esta análise as 266 manifestações restantes. As frequências absolutas e relativas apresentadas a seguir não podem ser somadas visto que, muitas vezes, um formulário apresentava, por exemplo, reclamações de mais de um setor, ou elogios a mais de um tipo de profissional, e assim por diante.

Verificou-se que é o alto índice de reclamações registradas pelos usuários do hospital, atingindo 83\% dos formulários (222 manifestações eram reclamações). As sugestões apontadas nas pesquisas totalizaram 23 registros (9\%). Por último ficaram os elogios, com 21 manifestações (8\%). Resultados como esse, isto é, elevado índice de reclamações em comparação ao baixo índice de elogios e sugestões, são comuns em serviços que buscam entender a opinião de clientes na área da saúde. O canal de comunicação se mostra como um meio de interação entre a população e os gestores desses serviços, onde quem se manifesta se sente livre para pontuar questões consideradas relevantes, especialmente ligadas à baixa qualidade dos serviços prestados pelas instituições, por meio de críticas e reclamações.

\subsection{Classificação das manifestações por categoria profissional}

Em relação a classificação das manifestações de acordo com a categoria profissional citada no documento, das 266 manifestações, 175 (66\%), não traziam informações quanto à categoria profissional dos possíveis envolvidos na no relato. Portanto, excluindo-se estes registros, a amostra total considerada válida para essa análise, passou a ser de 91 documentos. $\mathrm{Na}$ análise dos dados, é possível observar um elevado número de registros onde foi apontada a categoria médica (66 registros, correspondendo a $72 \%$ dos documentos que indicaram 0 profissional). Em seguida, foram citados os recepcionistas, com 19 registos (21\%). Já os enfermeiros, foram citados em 18 manifestações (20\%). As demais categorias profissionais mencionadas, atingiram apenas $5 \%$ da amostra inicial.

A importante reflexão que se permite realizar diante dos resultados do presente estudo, com relação aos resultados apresentados sobre a postura médica, é que muitos dos problemas elencados sobre a educação desses profissionais são os verdadeiros motivos que

Perspectivas em Gestão \& Conhecimento, João Pessoa, v. 9, n. 2, p. 85-111, maio/ago. 2019. 
levam os usuários a manifestarem queixas no canal de comunicação. Por outro lado, é possível que haja grande probabilidade dessas manifestações estarem relacionadas à falta de profissionais médicos, já que a diminuição do número de profissionais na grande maioria dos hospitais causa transtornos enormes para a assistência ao paciente. Por esta razão, é fundamental que gestores de serviços de saúde estejam atentos às questões relacionadas aos médicos, visto que estes refletem diretamente, na opinião do usuário, o nível de qualidade do atendimento do hospital.

\subsection{Classificação das manifestações por setor}

Foi possível verificar que 131 manifestações (49\%) não foram classificadas em relação ao setor do hospital ao qual as mesmas se referiam, devido à ausência da referida informação. Das 135 manifestações restantes, o primeiro setor mais pontuado pelos usuários foi o pronto socorro adulto, com 56 registros (41\%). O pronto socorro infantil apresentou 26 manifestações (19\%), seguido do ambulatório, com 19 registros (14\%), e a internação adulto, com 17 pontuações (13\%). Os demais setores representaram 34 manifestações (25\%).

Provavelmente este resultado se deve ao elevado número de atendimentos realizados por este setor, visto que a maioria dos pacientes internados nos hospitais passam primeiramente pelo pronto socorro, elevando assim a probabilidade deste setor ser bastante citado nos formulários de opinião, sendo esta, portanto, uma situação esperada e, de certa forma, compreensível, frente a atual situação da saúde pública no país.

\subsection{Classificação das manifestações quanto aos cinco "determinantes da qualidade"}

$\mathrm{Na}$ análise do comparativo entre as cinco dimensões que compõem tais "determinantes da qualidade", é possível afirmar que, na percepção do usuário, o que mais impacta negativamente nos serviços oferecidos pelo hospital são os fatores relacionados à 3 a Dimensão, que se refere aos aspectos de responsividade, com 85 registros (32\%). As principais queixas nessa dimensão se referiram à demora no atendimento e à falta de profissionais. 0 segundo "determinante da qualidade" mais apontado pelos usuários estava relacionado à 5 a Dimensão, os aspectos de empatia, com 83 registros (31\%). Mais especificamente, foram relatadas questões como a falta atendimento, de informação e de educação. 0 terceiro determinante mais apontado se referiu à 1a Dimensão, aspectos tangíveis, com 45 registros, (17\%), com destaque para relatos relacionados à falta de higiene local e condições inadequadas de infraestrutura. Por último, foram apontadas as dimensões de segurança (24 registros, $9 \%$ das manifestações) e confiabilidade (11 registros, $4 \%$ das manifestações).

Estes resultados levaram em consideração uma amostra válida de 266 manifestações, já que 35 registros (13\%), não puderam ser classificados quanto à dimensão, sendo então considerados como amostras "não identificadas". A Tabela 1 traz a classificação das manifestações de acordo com as cinco dimensões propostas por (PARASURAMAN; ZEITHAML; BERRY, 1988). 
Tabela 1: Classificação das manifestações de acordo com as cinco dimensões determinantes da qualidade

\begin{tabular}{lcc}
\hline DIMENSÃO & $\begin{array}{c}\text { FREQUÊNCIA } \\
\text { ABSOLUTA }\end{array}$ & $\begin{array}{c}\text { FREQUÊNCIA } \\
\text { RELATIVA }\end{array}$ \\
\hline TANGÍVEIS & 45 & $17 \%$ \\
CONFIABILIDADE & 11 & $4 \%$ \\
RESPONSIVIDADE & 85 & $32 \%$ \\
SEGURANÇA & 24 & $9 \%$ \\
EMPATIA & 83 & $31 \%$ \\
\hline
\end{tabular}

Fonte: Elaborada pelos autores

As dimensões mais citadas nesta pesquisa, foram aquelas relacionadas aos aspectos de responsividade (32\%) e empatia (31\%), que totalizaram $63 \%$ dos registros.

Estes resultados demonstram a necessidade de uma reflexão bastante pertinente aos serviços de saúde contemporâneos, já que a falta de profissionais médicos, o despreparo de colaboradores no atendimento ao público, e a falta de empatia dos funcionários em relação aos usuários, dentre outras questões relacionadas à humanização no atendimento, não são problemas isolados de uma unidade de serviço, sendo bastante comuns em muitos hospitais. Portanto, sugere-se aos dirigentes desses serviços a formulação de estratégias com vistas a estabelecer uma atenção especializada, afim de diminuir o número de supostas inconformidades apontadas nos canais de comunicação dos usuários desses serviços.

Durante a análise documental, quatro variáveis foram relevantes para os resultados desta pesquisa. A primeira se referiu ao atendimento/geral ou atendimento/procedimento especializado, que pareceu relacionar-se diretamente com a forma de atendimento, e não com a prestação dos serviços especializados. Entende-se que o atendimento/geral compreende a organização do processo de trabalho e da forma de atendimento, padronização de normas e rotinas, fluxos de serviço, além de adequações institucionais em geral. Mesmo com toda complexidade, esta percepção é mais facilmente identificada pelo usuário, visto que foi a mais apontada. Já a avaliação do atendimento relacionado aos procedimentos especializados, geralmente relativas às técnicas profissionais, são difíceis de serem avaliados pelos usuários, já que a grande maioria desconhece o assunto, fazendo com que seu julgamento tenda a ser menos exigente. De qualquer forma, os resultados aqui apresentados confirmaram o fato de que o maior número de reclamações se relacionou a problemas no atendimento, e não nos serviços prestados.

A classificação da manifestação como reclamação, elogio ou sugestão, foi a segunda variável analisada neste trabalho. Os resultados mostraram que as reclamações totalizaram a grande maioria dos registros analisados, sendo poucas as sugestões, e ainda menor o número de elogios. Este resultado foi condizendo com o esperado, visto que a fonte de dados analisados se referiu a um canal de comunicação entre usuários e gestores, e onde a liberdade de exposição de críticas e reclamações é fornecida a todos indiscriminadamente.

Outra variável considerada relevante neste estudo foi a categoria profissional envolvida no atendimento, estando os médicos envolvidos na maioria das reclamações associadas ao serviço prestado pelo profissional, seguidos dos funcionários das recepções e do pessoal da enfermagem. Os médicos, no contexto do atendimento hospitalar, são "elementos" chave para uma boa assistência. Quaisquer que sejam as falhas neste processo, tais como a falta desses profissionais, a demora no atendimento em detrimento ao baixo número de profissionais, dentre outras questões, pode gerar, consequentemente, inevitáveis reclamações nos canais de comunicações dos clientes.

Perspectivas em Gestão \& Conhecimento, João Pessoa, v. 9, n. 2, p. 85-111, maio/ago. 2019. 
Outra variável observada se relaciona com o setor mais mencionado nas reclamações, que foi o pronto socorro adulto. Esse é um resultado esperado, pois o alto número de atendimentos realizado no referido setor aumenta a chance de ocorrência de um grande número de reclamações dos serviços. Tal fato provavelmente se deve à falta de médicos, escassez de recursos técnicos e materiais em Unidade Básicas de Saúde. Esses e muitos outros motivos levam diversos pacientes a procurarem soluções de saúde em outras unidades, inclusive as de alta complexidade, como é caso do hospital foco desta pesquisa. Estes entraves contribuem diretamente para que haja sobrecarga de atendimentos, que por sua vez impacta negativamente na qualidade, refletindo no aumento do número de reclamações relacionadas ao referido setor.

Segundo a proposta metodológica deste trabalho, o desk research observou como principal parâmetro para análise, a classificação das manifestações segundo os "determinantes da qualidade". Os resultados demonstraram que a grande maioria das reclamações eram referentes aos aspectos de responsividade, dados confirmados pela grande quantidade de queixas referentes à demora no atendimento, seguidas das queixas relacionadas à falta de profissionais. A segunda dimensão mais pontuada, os aspectos de empatia, apresentou resultados muito próximos do que foi observado com relação à responsividade. Esta foi mencionada especialmente quando os usuários se referiram à falta de individualização no atendimento, além da comunicação ineficaz. Ocorreram relatos de inadequações quanto à forma de tratamento aos usuários, que não foi considerada para um ambiente hospitalar.

Os aspectos de responsividade e empatia foram os mais apontados. Contudo, é fundamental a reflexão sobre a institucionalização tanto das políticas de qualidade quanto das políticas de humanização no atendimento, já que estas, ao serem institucionalizadas, contribuem efetivamente para obtenção de resultados satisfatórios sob os aspectos que determinam a qualidade dos serviços.

Os aspectos tangíveis receberam uma pontuação que os classificou em terceiro lugar. Os dois principais itens apontados pelos usuários foram a falta de infraestrutura e os problemas relacionados à higiene hospitalar. $\mathrm{Na}$ infraestrutura, foram abordadas questões referentes a falhas no sistema som, que é comumente utilizado na chamada dos pacientes no momento das consultas e procedimentos no pronto socorro. Também ocorreram manifestações negativas relacionadas à falta de cadeiras de rodas, além de cadeiras mais confortáveis para acompanhantes. Ainda, a poluição sonora foi mencionada como um incômodo para os usuários do hospital.

Muitos dos aspectos tangíveis mencionados nos formulários estão associados a fatos gerenciais, como por exemplo, diversos problemas vinculados à forma de trabalho dos funcionários de empresas terceirizadas. Algumas soluções poderiam ser implementadas pelos gestores responsáveis pela unidade hospitalar, caso os mesmos possuíssem maior autonomia para tomar decisões. Entretanto, considerando a importância das instalações físicas, equipamentos e ambiente apropriado para um serviço hospitalar, é de suma importância levar em conta todas essas manifestações, afim de buscar formas de melhorar os processos de trabalho existentes na instituição.

Os dados mostram que, em relação aos aspectos segurança e confiabilidade, os índices de reclamações foram relativamente baixos, ocupando a quarta e quinta posições, respectivamente, entre as cinco dimensões dos determinantes da qualidade. Este resultado leva a crer que muitos dos usuários se sentem seguros e confiam nos serviços prestados pelo hospital, ou mesmo que o julgam como um local de assistência segura, por entenderem que apresenta melhores condições de atendimento quando comparado, por exemplo, às UBS, que deveriam ser os locais onde o usuário buscaria atendimento.

É possível que, diante desse fato, haja um sentimento de "sentir-se seguro" ao ser atendido em um hospital de alta complexidade. Essa é uma reflexão que sugere uma revisão 
de outras dimensões apontadas nos resultados desta pesquisa, cujos índices se mostraram bastante insatisfatórios, tais como, a responsividade e a empatia no atendimento.

\section{CONCLUSÕES}

Considerando que esta pesquisa teve como foco gerar informações que poderão contribuir para a prática gerencial no hospital estudado, algumas sugestões foram listadas como possíveis estratégias para que se possa alcançar melhores resultados com relação aos aspectos que mais apresentaram queixas no Programa "Conte Comigo", com destaque especial para a responsividade e empatia no atendimento.

Para apontarmos as estratégias de melhoria relacionadas à demora no atendimento e à falta de profissionais, é importante considerarmos que a instituição estudada faz parte de uma rede de hospitais pertencentes à Coordenadoria de Serviços de Saúde e, portanto, tem como dever seguir as diretrizes predeterminadas pela Secretaria Estadual da Saúde (SES). Muitas das tomadas de decisão, mesmo que extremamente necessárias, envolvem negociações múltiplas, já que a contratação de profissionais, aumento do número de plantõesextra remunerados, dentre outras estratégias onde exista custo financeiro, não podem ser resolvidas somente em nível das gerências de unidade, mas sim, apenas com autorização da SES, que muitas vezes trabalha de maneira burocrática e morosa.

Em suma, algumas sugestões de estratégias gerenciais, oriundas da interpretação dos resultados da presente experimentação, poderão ser avaliadas e, quiçá, implementadas visando a obtenção de melhorias nos processos assistenciais da instituição. O Quadro 1 lista algumas dessas propostas, as quais se sugere que sejam analisadas pela direção do hospital estudado, afim de atender às manifestações registradas pelos usuários. Algumas propostas são em especial para o setor do PSA, visto que o mesmo, por motivos diversos e já apontados nesse trabalho, foi o local mais citado nas manifestações registradas pelos usuários no Programa "Conte Comigo".

Quadro 1: Propostas para a melhoria do atendimento no hospital

\begin{tabular}{|c|c|c|}
\hline DIMENSÃO & RECLAMAÇÃO & PROPOSTA \\
\hline \multirow[t]{2}{*}{ RESPONSIVIDADE } & Falta de profissionais & $\begin{array}{l}\text { - Contratação de profissionais } \\
\text { médicos por meio de terceirização de } \\
\text { serviços (PSA). } \\
\text { - Contratação de profissionais } \\
\text { enfermeiros por meio de concurso } \\
\text { público (PSA). }\end{array}$ \\
\hline & Demora no atendimento & $\begin{array}{l}\text { - Adequação do fluxo de admissão de } \\
\text { pacientes no pronto socorro adulto } \\
\text { (PSA), com acolhimento imediato por } \\
\text { profissionais capacitados para esta } \\
\text { atribuição. }\end{array}$ \\
\hline \multirow[b]{2}{*}{ EMPATIA } & $\begin{array}{l}\text { Falta de atendimento } \\
\text { "Cuidados e atenção } \\
\text { individualizada aos clientes". }\end{array}$ & $\begin{array}{l}\text { - Atenção individualizada no } \\
\text { atendimento ao usuário, por meio da } \\
\text { avaliação de "classificação de riscos". }\end{array}$ \\
\hline & Falta de informação & $\begin{array}{l}\text { - Interagir com os usuários por meio } \\
\text { da criação de um canal de } \\
\text { comunicação direta, como por } \\
\text { exemplo, "balcão de informações"; } \\
\text { - Criar um sistema de informação que }\end{array}$ \\
\hline
\end{tabular}

Perspectivas em Gestão \& Conhecimento, João Pessoa, v. 9, n. 2, p. 85-111, maio/ago. 2019. 


\begin{tabular}{|l|l|}
\hline & $\begin{array}{l}\text { proporcione uma comunicação eficaz } \\
\text { entre os gestores das diferentes } \\
\text { áreas, como intranet e reuniões } \\
\text { sistemáticas; }\end{array}$ \\
- Utilizar mecanismos que garantam \\
que as decisões tomadas pelos \\
gestores sejam disseminadas de \\
forma globalizada, com o apoio da \\
equipe de tecnologia da informação \\
(TI);
\end{tabular}

Fonte: Elaborado pelos autores

Uma das estratégias propostas está relacionada à contratação de profissionais da saúde, como médicos e enfermeiros. Justifica-se estas contratações em razão da demora no atendimento, que por muitas vezes está relacionada ao dimensionamento de profissionais, isto é, a relação do número de consultas e atendimentos médicos / enfermagem para o número de pacientes atendidos. Na atual condição, o número de atendimentos é muito maior do que o número de profissionais disponíveis. Contudo, a contratação de médicos por meio de concurso público não é uma tarefa fácil, visto que inúmeros concursos são realizados e, por diversos motivos, não há candidatos, ou mesmo os que são aprovados não aceitam ser efetivados. Portanto, sugere-se que, neste hospital, a contratação de novas equipes médicas seja feita por meio da terceirização de serviços, sendo este um modelo diferenciado de gerenciamento de recursos humanos, que não fornece a efetivação de profissionais como nas contratações via concurso público, e proporciona uma maior flexibilidade no gerenciamento das equipes contratadas. Em relação à contratação de enfermeiros, esta poderá ocorrer por meio da abertura de novos concursos, desde que com critérios de seleção adequados, isto é, o candidato ao cargo deverá apresentar título de especialista em urgência e emergência válido no território nacional. Sobretudo, quaisquer que sejam as formas de contratação, estas são considerada necessárias para o presente momento, já que demanda excede a capacidade máxima de atendimento.

Conforme já mencionado, a demora no atendimento é uma não conformidade atrelada a muitas outras variáveis, como a alta demanda, muitas vezes acima da capacidade de atendimento, falhas dos processos de trabalho, como a não padronização de protocolos e rotinas, inadequações de fluxos de admissões, dentre outras. O processo de admissão de pacientes no pronto socorro (PS), repercute muitas vezes em queixas nos canais de comunicação dos usuários. Propõe-se que o fluxo do PS seja modificado e, para tal, devem ocorrer algumas mudanças no local, especialmente relacionada à forma de admissão dos pacientes. Sugere-se que, após aquisição de uma senha, o paciente seja acolhido por um enfermeiro, que fará o atendimento por classificação de risco, seguindo um protocolo institucional para esta avaliação. Após o acolhimento, o paciente será orientado a seguir 0 fluxo, quando então deverá se dirigir ao setor de recepção, caso seja possível, onde serão preenchidos todos os dados os formulários necessários para que se possa dar continuidade ao atendimento. A seguir, os colaboradores da recepção o conduzirão ao consultório médico, conforme especialidade definida no momento da classificação de riscos. Ao término da consulta médica, geralmente após a verificação dos resultados de exames, o paciente receberá alta hospitalar, ou será encaminhado ao setor de internação, sendo esta uma decisão de competência médica.

Vale ressaltar que, com a nova proposta, casos de urgências e emergências serão atendidos com mais eficiência, pois o fluxo padronizado por classificação de riscos 
proporcionará o primeiro contato com um profissional capacitado, que por suas competências, saberá avaliar com presteza o atendimento emergencial se fará necessário.

$\mathrm{O}$ acolhimento do paciente por classificação de risco traria para o processo assistencial uma maior agilidade e, principalmente, segurança no atendimento. A agilidade se daria pelo fato de que os enfermeiros designados para tal atribuição são preparados para identificar sintomas de doenças, classificando-as por prioridade de atendimento. Dessa forma, vislumbrase a redução das reclamações mais apontadas neste trabalho, associadas à responsividade $\mathrm{e}$ empatia no atendimento.

Outra proposta, se refere à inconformidade relacionada ao fornecimento de informações. Sugere-se a criação de "balcões de informações", que deverão ficar posicionados estrategicamente em dois pontos essenciais do hospital: o saguão do prédio principal, e a entrada do PSA. Entende-se que, com a execução dessa medida, haverá uma significativa diminuição de reclamações referentes à falta de informações, fortemente apontadas nesta pesquisa.

É importante ressaltar que, para qualquer implementação ou mudança no modelo de atendimento, o planejamento deve ser visto como prioridade, englobando treinamentos e capacitações que são essenciais para o sucesso das propostas sugeridas.

\section{CONSIDERAÇÕES FINAIS}

Acredita-se que as tomadas de decisão gerenciais devem abranger a instituição na sua totalidade. Dessa forma, sugere-se aos dirigentes que juntem esforços em prol da institucionalização de uma nova cultura organizacional, baseada na qualidade hospitalar e humanização no atendimento. Com o seguimento de tais diretrizes, certamente ocorrerão melhorias significativas não só nos aspectos apontados pelos usuários nesta pesquisa, mas em todos os aspectos nos quais se baseiam os determinantes da qualidade dos serviços.

Espera-se que os resultados deste trabalho possam realmente contribuir para a melhoria do atendimento no hospital. Todavia, é fato que são muitas as dificuldades na busca por resultados de excelência. Sobretudo, é fundamental que os dirigentes da instituição analisem as propostas aqui apresentadas.

De caráter metodológico, uma importante limitação foi a estratégia de coleta de dados adotada. Por conveniência, a análise documental se limitou apenas a um canal de comunicação entre usuários e gestores do hospital. Neste trabalho, poderiam ter sido utilizadas pelo menos três fontes diferentes de dados, o que caracterizaria uma triangulação estratégica. Para futuras pesquisas sugere-se abranger todos os canais de comunicação existentes, prevendo-se que, certamente, os resultados apresentarão uma dimensão muito mais significativa para análise da satisfação" dos usuários em relação aos serviços oferecidos na instituição.

Com relação ao instrumento de coleta de dados, por se tratar de um impresso no formato "aberto", não existiam campos específicos para que o usuário sinalizasse o setor, o serviço ou o profissional ao qual se referia a sua manifestação. Esta limitação não pode ser sanada no momento, visto que o formulário é padronizado pela Secretaria Estadual da Saúde SES.

Apesar das limitações, considera-se que os objetivos da pesquisa foram atingidos, assim como também a questão de pesquisa foi respondida. Vários fatores contribuíram para a ocorrência de um elevado registro de manifestações negativas no Programa "Conte Comigo", especialmente relacionadas aos aspectos responsividade e empatia. Apesar disso, há como melhorar a qualidade da assistência e, consequentemente, reduzir o número de reclamações, bastando para tal que a instituição reúna esforços visando alcançar os níveis de qualidade e humanização no atendimento considerados adequados.

Perspectivas em Gestão \& Conhecimento, João Pessoa, v. 9, n. 2, p. 85-111, maio/ago. 2019. 


\section{REFERÊNCIAS}

ALMEIDA, H. M. DE S. Programa de qualidade do governo federal aplicado à saúde. Revista de Administração em Saúde, v. 3, n. 12, p. 5, 2001.

ARAUJO, C. A. S.; DOS SANTOS FIGUEIREDO, O. H.; FIGUEIREDO, K. O que Motiva os Hospitais Brasileiros a Buscar a Acreditação? Revista de Gestão em Sistemas de Saúde, v. 4, n. 1, p. 1728, 2015.

ARAUJO, C. A. S.; FIGUEIREDO, O. H. D. S.; FIGUEIREDO, K. F. O que motiva os hospitais brasileiros a buscar a acreditação? Anais, SIMPOI, p. 16, 2013.

BALSANELLI, A. P.; JERICÓ, M. DE C. Os reflexos da gestão pela qualidade total em instituições hospitalares brasileiras. Acta Paul Enferm, v. 18, n. 4, p. 397-402, 2005.

BARBOSA, E. R.; BRONDANI, G. Planejamento estratégico organizacional. Revista Eletrônica de Contabilidade, v. 1, n. 2, p. 123, 2004.

BEBER, S. J. N. Estado atual dos estudos sobre a satisfação do consumidor. Encontro da Associação Nacional De Pós-Graduação E Pesquisa Em Administração, v. 23, p. 15, 1999.

BITTAR, O. J. N. V. Gestão de processos e certificação para qualidade em saúde. Revista da Associação Médica Brasileira, v. 46, n. 1, p. 70-76, 2000.

BRANDÃO, H. P.; GUIMARÃES, T. DE A. Gestão de competências e gestão de desempenho: tecnologias distintas ou instrumentos de um mesmo construto. RAE, v. 41, n. 1, p. 9, 2001.

CLETO, R. L. Qualidade percebida e satisfação dos pacientes nos meios complementares de diagnóstico e terapêutica do serviço de oftalmologia do Hospital CUF Descobertas/Centro Hospitalar de Lisboa Central, EPE: um contributo para a validação de um questionário. p. 107, 2014.

COLAUTO, R. D.; BEUREN, I. M. Proposta para avaliação da gestão do conhecimento em entidade filantrópica: o caso de uma organização hospitalar. Revista de Administração Contemporânea, v. 7, n. 4, p. 163-185, 2003.

CORREA, H. L.; CAON, M. Gestão de serviços. São Paulo: Atlas, 2002.

COUTINHO, A. A. P.; CECÍLIO, L. C. DE O.; MOTA, J. A. C. Classificação de risco em serviços de emergência: uma discussão da literatura sobre o Sistema de Triagem de Manchester. Revista Médica de Minas Gerais, v. 22, n. 2, p. 188-198, 2012.

DA ROCHA, R. A. et al. Acreditação dos hospitais das cidades sede brasileira na copa do mundo de futebol em 2014. Revista de Ciências da Administração, v. 13, n. 30, p. 178-197, 2011.

DA SILVA, F.; MATIAS, V. N.; GONZALEZ, I. V. D. P. A gestão por competência como modelo gerencial para o alcance dos objetivos organizacionais: um estudo de caso em uma empresa de telecomunicações. Destarte, v. 4, n. 2, p. 20, 2014. 
DE MOURA, G. M. S. S.; LUCE, F. B. Encontros de serviço e satisfação de clientes em hospitais. Revista Brasileira de Enfermagem, v. 57, n. 4, p. 434-440, 2004.

DE OLIVEIRA, S. M. Correlação entre atuação de gerentes de $\mathrm{SI}$ e aspectos gerenciais considerados importantes. Transinformação, v. 12, n. 2, p. 22, 2012.

DE PAULA BAPTISTA, P.; DA SILVA, W. V.; GOSS, L. P. Qualidade percebida e seus impactos sobre a satisfação, confiança e lealdade: um estudo com varejistas eletrônicos de serviços de download gratuito. Revista de Ciências da Administração, v. 13, n. 30, p. 249-277, 2011.

DE SOUSA, M. S. et al. Indicações e Tempo de Permanência em Internação Pós-Cirúrgica em um Hospital Público da Cidade de São Paulo - SP. Revista de Gestão em Sistemas de Saúde, v. 1, n. 1, p. 108-115, 2012.

DE SOUZA, C. C. et al. Classificação de risco em pronto-socorro: concordância entre um protocolo institucional brasileiro e Manchester. Revista Latino-Americana de Enfermagem, v. 19, n. 1, p. 26-33, 2011.

DONABEDIAN, A. Basic approaches to assessment: structure, process and outcome. In: Explorations in Quality Assessment and Monitoring: The definition of quality and approaches to its assessment. Michigan: Health Administration Press, 1980. p. 77-125.

DOS SANTOS, C. M. et al. Acolhimento e classificação de risco nos serviços de urgência e emergência: limites e possibilidades uma questão para os enfermeiros. Biológicas \& Saúde, v. 4, n. 15, p. 25, 2014.

DOS SANTOS, Í. E. R.; ARRUDA, J. S. Análise do perfil profissional dos gestores dos hospitais particulares da cidade de Aracaju-SE. p. 17, 2012.

DUSSAULT, G. A gestão dos serviços públicos de saúde: características e exigências. Revista de Administração Pública, v. 26, n. 2, p. 8-19, 1992.

FADEL, M. A. V.; REGIS FILHO, G. I. Percepção da qualidade em serviços públicos de saúde: um estudo de caso. Revista de Administração Pública, v. 43, n. 1, p. 7-22, 2009.

FARIAS, S. A. DE; SANTOS, R. DA C. Modelagem de equações estruturais e satisfação do consumidor: uma investigação teórica e prática. Revista de Administração Contemporânea, v. 4, n. 3, p. 107-132, 2000.

FELDMAN, L. B.; GATTO, M. A. F.; CUNHA, I. História da evolução da qualidade hospitalar: dos padrões a acreditação. Acta Paul Enferm, v. 18, n. 2, p. 213-9, 2005.

FERNANDES, A. C. B. C. Competências Gerenciais de Enfermeiros de uma Instituição Hospitalar de Belo Horizonte. Dissertação (Mestrado em Administração). Faculdade Novos Horizontes, Belo Horizonte, MG, Brasil, 2012.

FLEURY, M. T. L.; FLEURY, A. Construindo o conceito de competência. Revista de administração contemporânea, v. 5, n. SPE, p. 183-196, 2001.

GASTAL, F. A influência da satisfação e dos custos de mudança na lealdade do cliente. Dissertação (Mestrado). Universidade Federal do Rio Grande do Sul, 2005. 
GITLOW, H. S. Planejando a qualidade, a produtividade e a competitividade. Quality Mark, 1993.

GOUVEIA, G. C. et al. Satisfação dos usuários com a assistência de saúde no estado de Pernambuco, Brasil, 2005. Ciência \& Saúde Coletiva, v. 16, n. 3, p. 1849-1861, 2011.

GRÖNROOS, C. Marketing: gerenciamento e serviços: a competição por serviços na hora da verdade-Tradução de Cristina Bazán. Rio de Janeiro: Campus, 1995.

IBAÑEZ, N. et al. Organizações sociais de saúde: o modelo do Estado de São Paulo. Ciência \& Saúde Coletiva, v. 6, n. 2, p. 391-404, 2001.

JESUS, L. A. R. DE. Percepção da qualidade e satisfação dos utentes inscritos nos cuidados de saúde primários do concelho de Vila Real. Dissertação (Mestrado em Enfermagem Comunitária), p. 111, 2015.

JUNIOR, I. P. G.; PENHA, L. M.; SILVA, C. M. A Importância da Tecnologia da Informação como Ferramenta para o Processo da Gestão Hospitalar no Setor Privado: Um Estudo de Caso em uma Organização Hospitalar em Feira de Santana (BA). Revista de Gestão em Sistemas de Saúde, v. 2, n. 1, p. 91-115, 2013.

KERNER, R. Comportamento de consumo de serviço nas diferentes fases da lealdade. Trabalho de conclusão do curso de graduação em Administração da Universidade Regional do Noroeste do Estado do Rio Grande do Sul - UNIJUÍ, p. 111, 2015.

LEONARDO, J. M. A. A guerra do sucesso pelos talentos humanos. Revista Produção, v. 12, n. 2, p. 42-53, 2002.

LOPES, E. L. Avaliação do impacto da qualidade de serviços na lealdade dos consumidores de materiais para construção civil: aplicação dos modelos Servqual e RSQ em homecenters Paulistanos. Universidade Nove de Julho, São Paulo, SP, Brasil, 2007.

MANZO, B. F.; BRITO, M. J. M.; DOS REIS CORRÊA, A. Implicações do processo de Acreditação Hospitalar no cotidiano de profissionais de saúde. Revista da Escola de Enfermagem da USP, v. 46, n. 2, p. 388-394, 2012.

MARIA, D. O movimento pela qualidade nos serviços de saúde e enfermagem. Rev Bras Enferm, v. 59, n. 1, p. 84-8, 2006.

MARTINS, C. C.; WACLAWOVSKY, A. J. Problemas e Desafios Enfrentados pelos Gestores Públicos no Processo de Gestão em Saúde. Revista de Gestão em Sistemas de Saúde, v. 4, n. 1, p. 100-109, 2015.

MILAN, G. S.; TREZ, G. Pesquisa de satisfação: um modelo para planos de saúde. RAE Eletrônica, v. 4, n. 2, 2005.

NASCIMENTO, C. C. P. et al. Indicadores de resultados da assistência: análise dos eventos adversos durante a internação hospitalar. Rev Latino-am Enfermagem, v. 16, n. 4, p. 746-51, 2008.

OLIVER, R. L. Whence consumer loyalty? The Journal of Marketing, p. 33-44, 1999a.

Perspectivas em Gestão \& Conhecimento, João Pessoa, v. 9, n. 2, p. 85-111, maio/ago. 2019. 
PACHECO, R. S. Brasil: avanços da contratualização de resultados no setor público. Congreso internacional del clad sobre la reforma del estado y de la administración pública. Anais [...]. 2006. Disponível em: http://conversandosobregestao.mg.gov.br/images/anexos/gr/7.a2006\%20egina\%20pacheco.pdf. Acesso em: 27 mar. 2015.

PARASURAMAN, A.; ZEITHAML, V. A.; BERRY, L. L. A conceptual model of service quality and its implications for future research. The Journal of Marketing, p. 41-50, 1985.

PARASURAMAN, A.; ZEITHAML, V. A.; BERRY, L. L. Servqual. Journal of retailing, v. 64, n. 1, p. 12-40, 1988.

PASCHE, D. F.; PASSOS, E. A importância da humanização a partir do Sistema Único de Saúde. Revista de Saúde Pública de Santa Catarina, v. 1, n. 1, p. 92-100, 2008.

PERDICARIS, P. R. Contratualização de resultados e desempenho no setor público: a experiência do Contrato Programa nos hospitais da administração direta no Estado de São Paulo. 2012.

RIOS, I. C. Humanização: a essência da ação técnica e ética nas práticas de saúde. Rev Bras Educ Méd, v. 33, n. 2, p. 253-62, 2009.

RIZZATTI, G.; PEREIRA, M. F.; AMARAL, H. C. M. A Influência da Liderança na Condução do Processo Implementação do Planejamento Estratégico: Estudo de Caso no Hospital Universitário da Universidade Federal de Santa Catarina. Revista Ibero-Americana de Estratégia, v. 11, n. 2, p. 170-196, 2012.

RODRIGUES, F. G. Marketing hospitalar, é possível? Rio de, p. 30, 2001.

RODRIGUES, M. K. et al. Autoavaliação SINAES: Uma Estratégia De Gestão De Um Hospital Universitário. Avaliação: Revista da Avaliação da Educação Superior, v. 19, n. 1, 2014.

SELEGHIM, M. R. et al. Avaliação de usuários sobre a qualidade dos serviços de um pronto socorro. Revista da Rede de Enfermagem do Nordeste-Rev Rene, v. 11, n. 3, p. 10, 2012.

SILVA, A. M. DA. A evasão de clientes e soluções para a sua fidelização: um estudo de caso na agência do Banco Alfa da cidade de Crissiumal - RS. 2010. p. 48.

TONTINI, G. Interação de atributos atrativos e obrigatórios de um serviço na satisfação do cliente. Revista Produção, v. 18, n. 2, p. 112-125, 2008.

TONTINI, G. et al. Satisfação com serviços hospitalares como fator estratégico de gestão: uma abordagem não-linear. Gestão \& Planejamento-G\&P, v. 14, n. 3, p. 14, 2013.

VENDEMIATTI, M. et al. Conflito na gestão hospitalar: o papel da liderança. Ciênc Saúde Coletiva, v. 15, n. Supl 1, p. 1301-14, 2010a.

VENDRAMINI, R. C. R. et al. Segurança do paciente em cirurgia oncológica: experiência do Instituto do Câncer do Estado de São Paulo. Rev Esc Enferm USP, p. 827-832, 2010.

VIEIRA, K. F. et al. A utilidade dos indicadores da qualidade no gerenciamento de laboratórios clínicos. J Bras Patol Med Lab, v. 47, n. 3, p. 201-10, 2011. 
WINDLE, J.; MACKWAY-JONES, K. Don't throw triage out with the bathwater. Emergency Medicine Journal, v. 20, n. 2, p. 119-120, 2003.

ZEITHAML, V. A.; BITNER, M. J.; GREMLER, D. D. Marketing de Serviços: a empresa com foco no cliente. McGraw Hill Brasil, 2014. 